\section{Direct line lack of assurance}

\author{
Stephen Hancocks OBE \\ Editor-in-Chief
}

An article in the current issue of Dental Health, the journal of the British Society of Dental Hygiene and Therapy, speculates on the evolution of dental hygiene/therapy in the UK based on international comparisons. ${ }^{1}$ While acknowledging the well established model of teamwork in UK dental practice, the article considers the potential for an increase in delegation of tasks from dentist to hygienist/therapist. This accords with evidence that has been accumulating in the $B D J$ and other journals in recent times to the effect that therapists in particular are finding that they are not able to utilise the full range of their skills as generated in training and as permitted by regulation. In turn, this seems to be due either to a lack of understanding of their scope of practice by those dentists employing them or merely to a decision to use their abilities in apparently less than optimum ways.

No specific emphasis is given to the oft suspected desire to establish 'independent' practice, which is to say practice separate from and independent of the supervision of a dentist. This might be seen as significant at a time when employment is beginning to show signs of becoming harder to find and keep and when alternatives could be sought.

\section{A LACK OF CULTURAL COMPREHENSION}

Direct access by the public to a dental care professional (DCP) has little precedent in the UK, the exception being clinical dental technicians whose unconventional route to this position is in marked distinction to that of hygienists and therapists. Those without a comprehensive understanding of oral care delivery in the UK might be forgiven for thinking that such direct access could be of health value to patients through choice of provider and of potential economic advantage in reduced costs to either the patient and/or a third party payer such as the NHS or a private concern. However, neither of these constructs holds much credence on closer inspection.

Hygienists and therapists themselves, while aspiring to greater professional autonomy seem to express little desire to set up in independent practice and see themselves as part of the dental team, a concept that has particular strength and patient value in the UK. ${ }^{2}$ Indeed, before the current designation DCP they and their colleagues were titled, for a brief time, professionals complementary to dentistry (PCDs), recognising the harmonising role of each team member. This was a move on from a designation of professionals supplementary to dentistry which was used fleetingly as a carry-over from professionals supplementary to medicine but was considered not to fully express the value that was brought to the dental team by these practice members.
While there is every reason to examine other potential models of care provision, direct access would require cultural changes on several counts. Firstly the public would need to be made aware of what these DCPs were permitted to provide. A paper in the $B D J$ in 2010 revealed that only $10 \%$ of a sample of 1,000 adults recognised dental therapists as a professional group and that no one correctly identified their professional duties. $^{3}$ Of those who had experienced treatment by a dental therapist there was a high degree of satisfaction, which might be reasonably expected of them as professionals. However, about half the patients expected to pay less for a filling placed by a DCP than by a dentist despite the fact that the restoration should be of equally good standard regardless of the operating clinician. This does beg the question as to whether patients would voluntarily seek direct care in this way and if so, whether their expectation to pay less would make independent practice any sort of viable business alternative. Given the current surly reluctance of banks to lend to even well established enterprises it seems unlikely that a speculative new venture such as this would find much favour, arguably not even in better economic times.

More to the point is whether or not it would be in the interests of a patient's oral health to attend such a professional in a situation adrift from the full examination and diagnostic experience of a dentist. While acknowledging that in their training therapists (27 months) and hygienists (24 months) receive intensive instruction in the appropriate procedures, they are not given full education in terms of whole body systems, physiology, pathology and so forth. Consequently, and rightly, the need for top-down application of a diagnostic sieve process from a dentist is the model perceived by and supported in this vision of training for oral care delivery. Would the prospect of a DCP in independent practice cautioning a patient from the outset that they would have to see a dentist in order to get a full oral health overview promote much confidence in, or actually serve to undermine that DCP's professional status? Economic woes or not, it seems unlikely that this model has much going for it any time soon.

DOI: $10.1038 /$ sj.bdj.2012.51

1. Gough N. What international comparisons might contribute to the evolution of dental hygiene/therapy practice in the UK? Dent Health 2012; 51: 6-10.

2. Turner S, Ross M K, lbbetson R J. Dental hygienists and therapists: how much professional autnomy do they have? How much do they want? Results from a UK survey. Br Dent J 2011; 210: E16.

3. Dyer T A, Humphris G, Robinson P G. Public awareness and social acceptability of dental therapists. Br Dent J 2010; 208: E2. 